\title{
The CADMUS experiment in the frame of the BEXUS Programme: an educational perspective
}

\author{
G. Megías Homar, R. Bahí Buhigas, R. M. García Alarcia, G. Pascual López, A. Teixidó Bonfill \\ Universitat Politècnica de Catalunya - BarcelonaTech \\ Barcelona, Spain \\ cadmus@cadmusbexus.com
}

\begin{abstract}
CADMUS was a student-made experiment with the aim of measuring the flux of muons at different altitudes and experimentally verifying time dilation, one of the effects predicted by the Special Relativity Theory. It was developed in the frame of the REXUS/BEXUS Programme and flew to the stratosphere on a high-altitude balloon in October 2017. This paper discusses its development, from inception to launch, from the perspective of space educational activities.
\end{abstract}

Keywords-student-made experiment; particle detector; cloud chamber; muons; Special Relativity Theory; time dilation; REXUS/BEXUS Programme; stratosphere; high-altitude balloon; education

\section{INTRODUCTION}

The Cloud chamber for high Altitude Detection of Muons Under Special relativity effects (CADMUS) was a studentmade experiment consisting of a cloud chamber and a video recording system, with the aim of measuring the flux of muons from the ground up to the stratosphere, and through the computation of muons' half-life, verifying one of the effects described by Albert Einstein's Special Relativity Theory: time dilation.

The idea was born during the fall of 2016 out of a small group of Engineering Physics' bachelor students, and it was then presented to the REXUS/BEXUS Programme, which allows university students to fly their experiment ideas to the border of space, either with a sounding rocket or with a stratospheric balloon. This programme entails an exigent process of selection and supervision ensuring that students succeed throughout the development of the experiment.

The team behind CADMUS was composed of five secondyear university students, two of them studying Engineering Physics, two of them studying Engineering Physics and Mathematics, and the fifth one studying Aerospace Engineering and Telecommunications Engineering. Thus, the idea was to have a team with a strong background on physics to define the proper performance requirements for such an experiment to produce valuable data, and to later conduct the scientific analysis of the results, but also with the engineering background required for the design and development of the experiment, specially with regard to the particularities of nearspace missions.

The selection committee of the REXUS/BEXUS Programme chose the experiment to fly on the stratospheric balloon of mission BEXUS 24 in December 2016. The project entered then into a one-year phase of design and development, passing a Preliminary Design Review (PDR) in March 2017, a Critical Design Review (CDR) in May 2017, an Integration Progress Review (IPR) in August 2017, and an Experiment Acceptance Review (EAR) in September 2017. CADMUS was finally launched on the $18^{\text {th }}$ of October of 2017 from the Esrange Space Center near Kiruna, Sweden.

Although the experiment could be controlled and its systems performed nominally during the flight, due to unforeseen causes that are explained in Section 4, no quality images of traces of muons could be captured, and thus, the scientific goal of measuring the flux of muons was not reached.

Through the sections of this article, the idea behind the experiment, its design and development, as well as a description of the launch campaign and its results, are presented. Each section tries to compare the described processes to the educational background of the team members in terms of university courses' syllabus. Also, a particular section focusing on outreach and educational activities performed during the project is included.

\section{About REXUS/BEXUS:}

The REXUS/BEXUS programme is realised under a bilateral Agency Agreement between the German Aerospace Center (DLR) and the Swedish National Space Agency (SNSA). Through the collaboration with the European Space Agency (ESA), the Swedish share has been made available to students from all ESA Member or Cooperating States. EuroLaunch, the cooperation between the Esrange Space Center of SSC and the Mobile Rocket Base (MORABA) of DLR, is responsible for the campaign management and operations of the launch vehicles. Experts from DLR, SSC, ZARM, and ESA provide technical and logistic support to the student teams throughout the project.

\section{THE EXPERIMENT}

Muons are elementary particles, from the family of leptons, which primarily originate at $15 \mathrm{~km}$ of altitude due to the interaction of cosmic rays with the atmosphere. They are unstable -with a half-life of $2.2 \mu$ s- and negatively charged particles.

Given their short half-life of $2.2 \mu \mathrm{s}$, by applying Newton's laws of motion it can be shown that it is impossible to detect muons at sea level, since they should have disintegrated long before reaching the ground. In other words, Newton's laws of 
motion tell that a particle moving at about the speed of light, such as a muon, will take more than $2.2 \mu \mathrm{s}$ to travel $15 \mathrm{~km}$. However, muons are actually detected at sea level.

This challenging fact is explained by the Special Relativity (SR) Theory. One of the effects described by this theory is time dilation, which can be described as time seeming to pass slower for observers at a different system of reference with respect to objects moving at velocities close to the speed of light. This would explain why muons are able to reach the ground: as they are travelling close to the speed of light, their half-life seems to pass more slowly than $2.2 \mu \mathrm{s}$ for us, and thus, they are able to travel longer distances. By measuring the flux of muons at different altitudes, their half-life can be calculated.

This SR effect and, more generally, the overall SR Theory are normally not included in the syllabus of secondary education courses in Physics. Basically, the courses focus in the introduction of Newtonian physics to students. At university level, Relativity theories are covered in the degrees of Physics and Engineering Physics. Relativity is normally taught as an elective course in the third or fourth year of the degree. Although teaching the principles of such theory to preuniversity students is clearly beyond the scope and possibilities of those courses, exposing students to the limitations of Newton's theories can be beneficial, specially in terms of understanding how scientific theories evolve and how they represent the best approximations that we have so far for explaining certain complex phenomena. Experimenting with the time dilation effect that muons undergo can be thus, a good introduction to those limitations of Newtonian physics.

With a similar goal, and to a greater extent, CADMUS experiment wanted to empirically reconfirm the time dilation effect in muons, by measuring the flux of muons mentioned before. In order to do so, a cloud chamber was built. A cloud chamber is a type of particle detector which consists of a pressurised chamber, filled with alcohol, cooled at the bottom and heated at its top. The gradient of temperature across it generates an atmosphere of supersaturated alcohol vapour. Due to this atmosphere, charged particles such as muons leave traces as they traverse the chamber. Depending on the type of particle, the trace will be more or less straight and thick. There are many designs of cloud chambers, some being quite rudimentary and some others being more complex. Also, apart from cloud chambers, simple electronic muon detectors can be built. Some articles such as [1] and [2] propose simple ways in which particle detectors can be easily built, suitable for the context of a secondary school laboratory and also a university one. The design of the cloud chamber of CADMUS is explained in Section 3.

\section{ENGINEERING DESIGN}

In this section, the design of the experiment is described grosso modo. It is divided into diverse subsections (mechanical, electronics, thermal, software) in which the focus is set into different experiment's subsystems.

\section{A. Mechanical design}

The experiment is composed of three different structures: the primary structure, the secondary structure, and the tertiary structure, each of them serving specific purposes.

The primary structure is the skeleton of the experiment. It withstands all the payloads of the experiment, and it allows the connection of the experiment to the gondola of BEXUS 24, where other mission experiments are placed. The secondary structure protects the experiment from the outside, both from impacts and extreme temperatures. It is compounded of 6 aluminium panels that cover all the primary structure. Over the aluminium panels, thicker Basotect ${ }^{\circledR}$ panels are placed to thermally protect the experiment. These panels are also covered by a thin layer of thermal blanket. The tertiary structure is internal and consists of mountings that support the electronic subsystems and the recording camera.

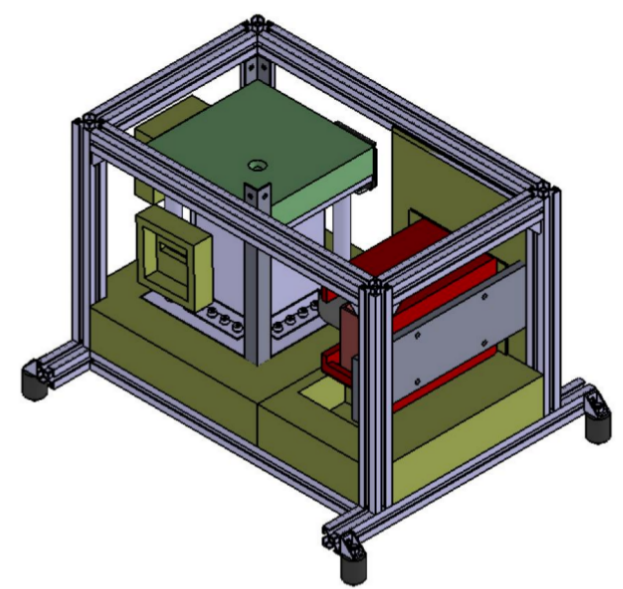

Fig 1: Design of the experiments primary structure (in grey) and tertiary structure (in red, yellow, and green). The cloud chamber is also visible in lighter gray.

Finally, inside the experiment, the cloud chamber also occupies an important place. Below the cloud chamber, there is a structure specifically designed to contain the cooling dry ice.

The aluminium bars of the primary structure and the aluminium panels of the secondary structure were designed using CAD tools -in particular, SolidWorks-, and were sent to a factory for its production. In fact, the use of CAD tools such as SolidWorks is taught in universities in first-year courses covering technical drawing, in degrees such as Aerospace engineering, Industrial engineering, and Mechanical engineering, among others. Thus, the team had the necessary background to produce such designs, and the project was a good opportunity to put into practice what had been learnt at class before. Other than that, the pressurised chamber was designed and built by ZARM.

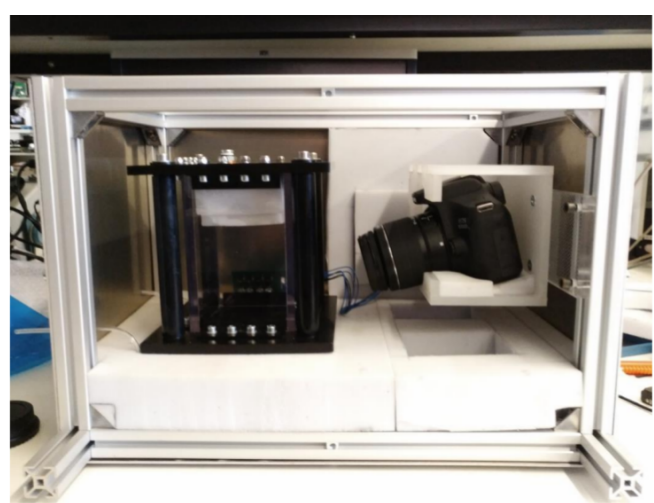


B. Electronics design

The principal goals of the electronic subsystem are to power the heaters on top of the cloud chamber so that the supersaturated alcohol atmosphere can be created, power the video recording camera which has to capture muon traces, and illuminate the chamber for the videos to have the required quality. This subsystem also powers the experiment's computer, a Raspberry Pi which is able to control the heaters, camera, and lighting blocks, measure essential parameters of the experiment -such as temperatures- through sensors, save data, and transmit data to ground.

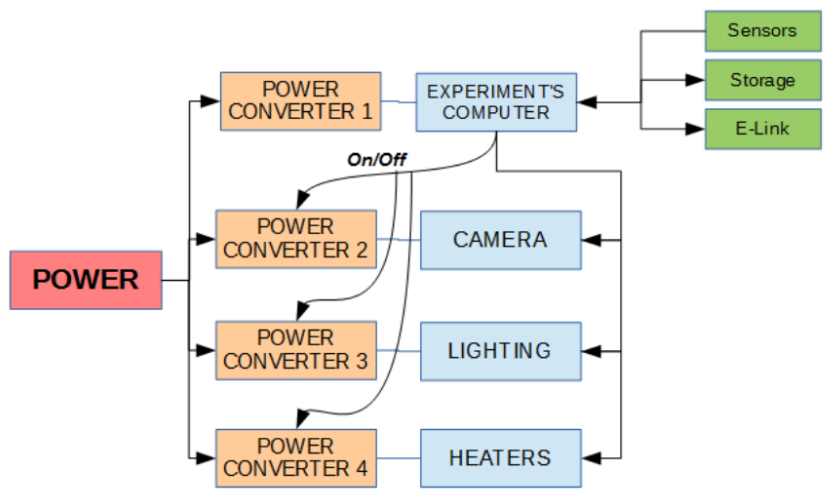

Fig 3: Block diagram of the components of the electronics subsystem and their interrelations.

In order to decrease the probability of losing the mission due to a failure in an electronic element, redundancy was implemented for some components, which were doubled. For instance, the Raspberry Pi, the heaters, the lighting block, and the sensors were doubled, and the auxiliary doubles could be turned on if the primary elements failed.

For each electronic subsystem, PCB were created using the free software tool KiCAD, and were sent to be printed at a factory. Sensors and electronic components such as DC-DC converters were also bought. Afterwards, in an electronics laboratory, everything was assembled and soldered on the printed PCB. A member of the team attended a soldering course given in the frame of the BEXUS programme, which helped gaining the necessary skills to properly solder components to the boards. Unlike soldering experience, team members already had basic knowledge on circuits theory and tools for the design and simulation of circuits from university courses. Degrees such as Telecommunications engineering, Electronics engineering, etc. but also Engineering physics include courses on circuit theory and electronics.

\section{Thermal design}

Maintaining the temperature inside the experiment in a specific range is important due to two reasons: to ensure that it is always in the working range of electronic components, so that they don't fail; and to ensure that the critical temperature gradient is maintained inside the cloud chamber. To attain this goal, the experiment counts with one passive thermal control system and one active thermal control system.

The passive thermal control goal is to maintain the internal temperature of the experiment within slow variations, and always above $-40{ }^{\circ} \mathrm{C}$, so that electronic components work properly. It has to protect from extreme outside temperatures, but also from extreme internal temperatures (those coming from the dry ice container and also the heaters above the cloud chamber). The passive thermal control is made up of Basotect ${ }^{\circledR}$ panels covering the experiment's exterior panels, and covered by Mylar blanket.

The active thermal control goal is to maintain the necessary temperature gradient inside the cloud chamber to generate the supersaturated alcohol vapour. It is an active thermal system, as it automatically checks for the temperature on top of the chamber and at its bottom, calculates the gradient of temperature between both points, and turns off or on the heaters accordingly, in a hysteresis loop, to obtain the desired gradient.

To check that the thermal design was good enough, heat transfer studies had to be performed. These studies were basic and based on thermodynamic calculations regarding materials' thermal conductivity and components' heat generation. The team relied on knowledge from Thermodynamics university courses, which are offered in a wide variety of engineering degrees, for instance those related to the team members (Engineering Physics and Aerospace Engineering) but also in others (such as Industrial Engineering).

\section{Software design}

Two important pieces of software were built for the experiment: the experiment's on-board computer software, and the ground segment control software.

The on-board software was programmed in Python and run in a Raspberry Pi. A watchdog ensured that the Python script run continuously. The main goals of the software were to continuously collect data from sensors, send it to the ground via an Ethernet link provided by BEXUS, and continuously read commands coming from the ground and act upon them by performing the necessary actions -turning on/off lighting, heaters, etc.-.

The ground software was coded in $\mathrm{C \#}$ and it run in a Windows 7 laptop. Its main purpose was to display information coming from the experiment, and allow the ground segment operator to send commands to the on-board computer.

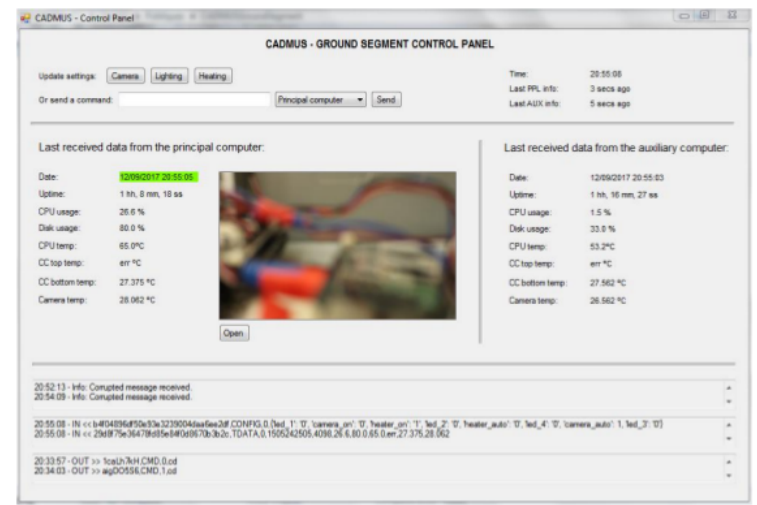

Fig 4: Picture of a test of the ground segment software, showing information incoming from the experiment. 
The team relied on knowledge coming from university programming courses, but also on experience gained by members while attending hackathons and other coding events, and while having worked on previous personal projects. All engineering degrees offer courses on programming, but a Telecommunications Engineering course providing knowledge about $\mathrm{CH}$ and socket communication was of special interest for the ground segment software design. Engineering Physics studies also include a course on Python, which was useful for the on-board computer programming.

\section{LAUNCH CAMPAIGN \& RESUltS}

The launch campaign of CADMUS and all of the other experiments flying on mission BEXUS 24 took place from October $13^{\text {th }}$ to October $22^{\text {nd }}$ of 2017 . During these days, the experiment arrived at the Esrange Space Center near Kiruna, was assembled and prepared, and was tested to ensure that it worked properly and that it did not interfere with any other experiment flying on the same mission. After successful tests, the experiments of BEXUS 24 were launched on the $18^{\text {th }}$ of October. Hours after the launch, they were recovered and brought back to Esrange. A fast, first analysis of the recorded videos was performed by the CADMUS team. A brief presentation on the experiment's preliminary results was also given on the last days of the launch campaign.

During the course of the whole mission, the experiment transmitted the intended technical and scientific data regularly, and could be controlled through the use of predefined commands. Thus, it performed as expected from the engineering point of view.

However, the heaters present at the top of the cloud chamber -needed to create the temperature gradient for the isopropyl alcohol to supersaturate- had to be activated through a remote command moments before the launch, to ensure that the dry ice present at the bottom of the chamber would not melt before the launch, since a long time can pass from experiment start-up to the actual launch.

The heaters could not be turned on manually moments before the launch, as it was planned, due to the instability of the communications link to the experiment. The communications link used wireless technology and its power had to be reduced during the phase previous to the launch, to protect workers on the launch area from EM radiation, thus degrading its performance. Once the BEXUS 24 launched, the power of the communications link was increased to its nominal value, and the link started working properly again. The command to turn on the heaters could then be sent, but precious time had been lost, and the necessary gradient of temperature inside the cloud chamber took longer to create.

The necessary temperature gradient was finally obtained during the float phase of the mission, above $15 \mathrm{~km}$ of altitude. Thus, no traces could be formed in the cloud chamber during the ascent, the most interesting part of the flight. The descent was fast, and the recording camera was focused for ascent conditions -due to the consumption of dry ice at its bottom, the cloud chamber descends and the focus of the camera changes during the flight-, and no relevant data could be collected also during the descent.

\section{OUTREACH}

An important part of any BEXUS project is to communicate the experiment's existence, goals, development, and results, to the general public. It is not only important to learn by doing the project, but also to teach others. One of the first outreach activities was to explain the project to fellow students, professors, and administrative staff of Universitat Politècnica de Catalunya, our university. Thus, news were published on the websites of Engineering Physics degree, and the EETAC and CFIS schools.

Also, accounts on social media websites such as Facebook. Twitter, and Instagram were set up and information was posted regularly about the progress of the experiment development. The team also got in touch with the Communication Service of the university, which contacted press and media to share our story with them.

Following that, CADMUS appeared on newspapers, making it to the front page of La Vanguardia, the third most read newspaper in Spain (with about 600000 readers), on May $2^{\text {nd }} 2017$ [3]. It was featured on radio programmes such as Herrera in COPE, the second most listened morning radio show in Spain (with about 2 million listeners), El món a RAC1, the most listened in Catalonia region (with about 800000 listeners), and Informatius de Catalunya Ràdio [4]. It also appeared on TV programmes such as the nightly news Telediario in national television $L a 1$ (with about 2 million viewers) on May $2^{\text {nd }} 2017$ [5], and local Esplugues TV [6]. Thus, the project reached millions of people in Spain, who discovered more about muons, special relativity, and time dilation.

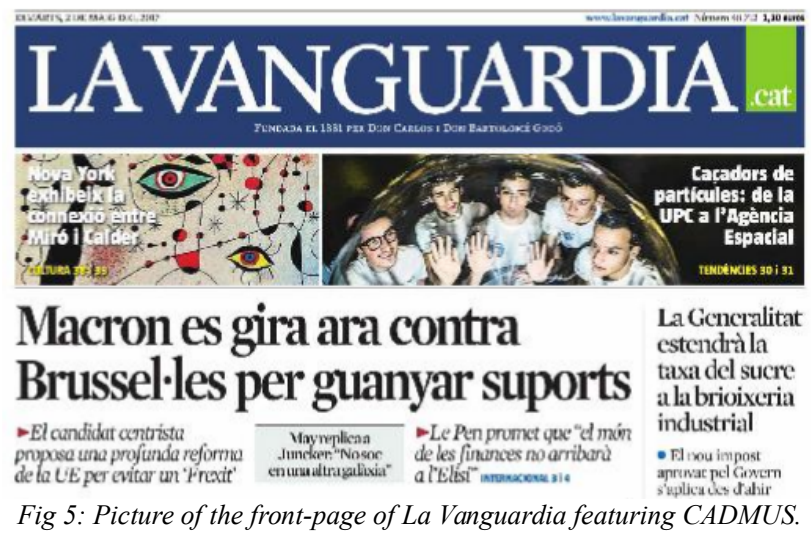

The project was not only mentioned by mass communication media, it appeared as well in specialised media such as Actualidad Aeroespacial (focused in aerospace news) [7], Fulls dels Enginyers (engineering news) [8], and Noticias de la Ciencia (science news) [9].

One of the outreach activities of the project consisted in visiting Rubén Dario's public primary school in Barcelona, Spain. A short talk was given to 30 primary students of $4^{\text {th }}$ grade ( 9 to 10 years-old). The talk was focused on explaining 
the scientific method to kids and to encouraging them to keep studying and to follow careers in science.

Previously, the teacher had worked with the students with adapted material regarding the project. The kids worked on the project topics from an interdisciplinary point of view, they read the newspaper article published by La Vanguardia, and draw and painted muons and cloud chambers, among other activities.

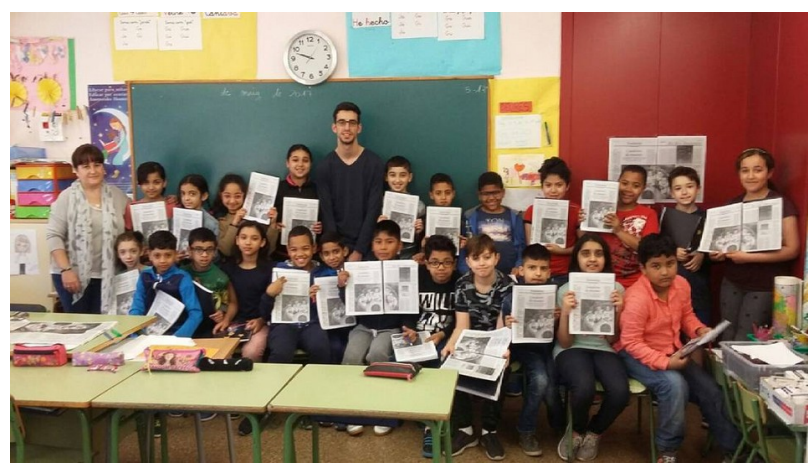

Fig 6: Picture of the teacher and kids from Rubén Dario's school and one of CADMUS members, after the talk.

\section{CONCLUSION}

The inception, the design, the development, the launch, and the results analysis conducted for CADMUS have revealed to be a truly remarkable educational activity, in which knowledge coming from different disciplines of science and engineering and learnt at diverse bachelor degrees was put into practice. Self-teaching also played a very important role, as many things had never been done before by team members.

The project gave as well its members a great opportunity to master skills at project management and outreach, and many other abilities not directly linked with science and technology (such as giving presentations, documenting the project, requesting funding, managing a budget, talking to material providers, etc.). Finally, the project also had a big external impact in terms of educating the general public, teaching millions of people in Spain about muons and special relativity, and inspiring little kids and attracting them to science.

Thus, CADMUS can only be described as a truly remarkable and positive educational experience, both internally and externally.

\section{AFTERWORD}

For detailed information about the experiment, more linked to its engineering design and less focused on its educational part, please refer to CADMUS' Student Experiment Documentation available at [10].

\section{ACKNOWLEDGMENT}

The team behind CADMUS would like to acknowledge the inestimable help of Fundació Cellex, Centre de Formació Interdisciplinària Superior (CFIS-UPC), Escola Tècnica
Superior d'Enginyeria de Telecomunicació de Barcelona (ETSETB-UPC), Escola d'Enginyeria de Telecomunicació i Aeroespacial de Castelldefels (EETAC-UPC).

A most grateful acknowledgement to all those professors and university staff who disinterestedly offered their time, support, and recognition to the project: our UPC mentor Prof. Toni Pascual Iserte, Prof. Quim Trullàs, Prof. Oscar Casas Piedrafita, Prof. Juan Carlos Collado and the Components and Systems for Communications (CSC) Group; Prof. Ramon Bragós Bardia, Prof. Alfonso Méndez, and the Electronic and Biomedical Instrumentation (IEB) Group; Blanca Veciana Gramunt and the Communication Service of Universitat Politècnica de Catalunya (UPC) and many more not mentioned here.

The authors also express appreciation for each of our Indiegogo crowdfunders. CADMUS is also grateful to Ateneu de Fabricació Les Corts, Praxair/HieloSeco.es and Alfredo Alarcia Arnaiz (In Memoriam).

Finally, the authors are thankful to all the engineers and professionals that supported us in the frame of the REXUS/BEXUS Programme: Hanno Ertel, Stefan Krämer, Dieter Bischoff and the team at ZARM, Koen DeBeule, and Alexander Kinnaird, Armelle Frenea-Schmidt, and all the team in charge of the REXUS/BEXUS programme organisation.

\section{REFERENCES}

[1] “How To Prove Einstein's Relativity For Less Than \$100”, Ethan Siegel, Forbes $(27 / 04 / 2017)$

https://www.forbes.com/sites/startswithabang/2017/04/27/how-to-proveeinsteins-relativity-for-less-than-100/

[2] "CosmicWatch::catch yourself a muon", Massachusetts Institute of Technology (MIT) - http://cosmicwatch.lns.mit.edu/detector

[3] "Cazadores de muones", Big Vang, La Vanguardia (02/05/2017) https://www.lavanguardia.com/ciencia/20170502/422207526766/estudia ntes-ingenieria-programa-fisica-agencia-espacial-europea-muones.html

[4] "Caçadors de muons", Informatius de Catalunya Ràdio, Catalunya Ràdio/CCMA $(14 / 05 / 2017)$ https://www.ccma.cat/catradio/alacarta/informatius-catalunyaradio/cacadors-de-muons/audio/961808/

[5] "Estudiantes de la Politécnica de Barcelona, a la caza de muones para probar a Einstein", Telediario, La 1/RTVE (02/05/2017) http://www.rtve.es/alacarta/videos/telediario/td2-020517-estudiantesupc/4003750/

[6] CADMUS at "Informatiu comarcal", ETV (26/04/2017) http://etv.alacarta.cat/informatiu-comarcal/capitol/26-abril-2017 (from minute $6: 12$ to $8: 16$ )

[7] "Estudiantes de la UPC buscan muones en la estratosfera para comprobar la teoría de la relatividad", Actualidad Aeroespacial (20/04/2017) - https://actualidadaeroespacial.com/20226-2/

[8] "Estudiants de la UPC, a la caça de muons a l'estratosfera per comprovar la teoria de la relativitat", Fulls dels Enginyers (20/04/2017) http://fullsdelsenginyers.cat/article/estudiants-upc-caca-muonslestratosfera-comprovar-teoria-relativitat

[9] "Estudiantes de la UPC, a la caza de muones en la estratosfera para comprobar la teoría de la relatividad", Noticias de la Ciencia (21/07/2017) - https://noticiasdelaciencia.com/art/23945/estudiantes-dela-upc-a-la-caza-de-muones-en-la-estratosfera-para-comprobar-la-teoriade-la-relatividad

[10] "Student Experiment Documentation (SED)", CADMUS (04/05/2018) http://cadmusbexus.com/wpcontent/uploads/2018/06/CADMUS SED.pdf 